\title{
STUDY ON THE VERTEBRAL COLUMN OF THE LARGE TOOTH FLOUNDER, PSEUDORHOMBUS ARSIUS (HAMILTON, 1822) COLLECTED FROM OMAN SEA
}

\author{
Laith A. Jawad \\ Manukau, Auckland, New Zealand \\ E-mail: laith_jawad@ @otmail.com
}

Received: 23-11-2013

\begin{abstract}
Based on morphometry, the vertebral column of Pseudorhombus arsius may be divided into four morphologically distinct regions. The biometrical study of the length, height and width of the successive vertebrae constituting the vertebral column of Pseudorhombus arsius allows characteristic vertebral profiles to be drawn. The differences in length of vertebrae present in different regions of the vertebral column cause regionalization in this structure. These morphological descriptive parameters express a morphotype which seems to have a functional link with the anguilliform mode of swimming of the large tooth flounder.
\end{abstract}

Key words: Morphometry, vertebral column, Pseudorhombus arsius, regionalization.

\section{INTRODUCTION}

Pseudorhombus arsius (the large tooth flounder) is considered among the most commercial importance fish species in Oman. Its landing in Sultanate of Oman showed a dramatic increase during the last decade to several hundred tons [17]. The study of the taxonomy of this species in general and the skeletal characters in particular have not been receiving considerable attention in this region so far.

Vertebrates show variation in the degree of regionalization of the vertebral column. Such differences in the morphology of vertebrae of different regions of vertebral column can be revealed by biometrical studies $[10,11,4]$. The vertebral column of actinopterygian fishes has two basic regions: the pre-anal abdominal region and the post-anal caudal region [7], with marked diversity in vertebral form within these regions $[2,6,7,18]$. The abdominal region may include, from anterior to posterior, occipital vertebrae that are incorporated into the skull through ontogeny, middle region vertebrae that are highly modified (e.g. Weberian apparatus in Ostariphysi and fused vertebrae in Syngnathoidei), and vertebrae that generally bear abdominal ribs. The uralregion includes vertebrae that bear haemal spines and ural vertebrae that bear hypurals. The locomotory function is linked to this regional pattern of vertebral structure of the vertebral column [20].

Among the important mechanical tasks that the vertebral column gets involved in is the fish locomotion [12, 14, 26]. During the developmental stages, this structure is subjected to different types of biological strains which seem to be expressed by local and specific morphological peculiarities $[4,10,11]$. Due to the strong anatomical and functional relationship with the trunco-caudal musculature $[13,14,23]$, it is worth to study the morphological characteristics of the vertebral column in order to reveal such relationship. 
Studying the morphology of the vertebral column of one more teleost species such the species in question will enrich the data base of this subject and make data available to check for morpho-functional hypotheses in this species. The aim of the present work is to study the biometry of the vertebral column of Pseudorhombus arsius collected from the Sea of Oman as there is no such information is available in the literature for this species.

\section{MATERIALS AND METHODS}

Vertebral column of 16 specimens of $P$. arsius ranging in total length between 140 and $220 \mathrm{~mm}$, caught from the vicinity of Muscat City at the Sea of Oman on July 2009, were studied. To prepare dry vertebral columns, the fish specimens were boiled to strip the flesh off the bone. Their vertebral column was brushed in running water. After drying, the vertebrae were separated, numbered and measured with a digital 1/100 caliper. Length (VL), height (VH) and width (VW) of each vertebra were measured; the length of the vertebra represents the distance along the mid-ventral line. This measurement is considered among the factors controlling the degree of the body's flexibility; the anterior height of vertebra ( $\mathrm{VH})$ corresponds to the maximum vertical length of the anterior side of the vertebrae; and the vertebral anterior width (VW) represents the maximum horizontal width across the anterior surface of vertebra. From these three measurements, it is possible to establish a vertebral profile which reflects the variation of these parameters along the vertebral axis $[4,9$, 17, 21]. To compensate forinter-individual variation and to facilitate future comparisons with other samples, even from other species, each vertebral measurement was converted into a vertebral index $\mathrm{V}_{\mathrm{i}}$ :

$$
\mathrm{V}_{\mathrm{i}}=\mathrm{P} / \mathrm{SL}
$$

Where, $\mathrm{P}$ is the vertebral parameter (VL, $\mathrm{VH}$ and VW) and SL the standard length of the fish. Profiles of the vertebral column were drawn by plotting VL, VH and VW against the ordinal number of the vertebrae.

The number of abdominal and caudal vertebrae was counted and the mean values for each region were calculated for each individual, then the species mean was calculated for abdominal vertebral number (AVN) and caudal vertebral number $(\mathrm{CVN})$. Abdominal vertebrae were defined as those that were cranial to vertebrae with separated haemal arches. The caudal region was defined as the region from the first fused haemal arch posterior to the last centrum including the ural centrum. The mean vertebral aspect ratio ( $\mathrm{AR}=$ centrum length/ centrum width) for each region was calculated for each individual. The means were then calculated for abdominal aspect ratio (AAR) and caudal aspect ratio (CAR).

\section{RESULTS}

All the sixteen specimens of Pseudorhombus arsius analysed here for gross morphology had 36 vertebral centra from cranial to caudal excluding the urostyle: 11 abdominal vertebrae, 26 caudal vertebrae and the urostyle (fig. 1). It is possible to divide the vertebral column of the species in question into four regions: postcranial (V1-V4), middle region (V5-V10), anterior caudal region (V11V21) and ural region (V22-V36). The limit between abdominal and caudal vertebrae is located at the level of vertebra number 11 . The 6 vertebrae of middle region define the abdominal region or truncal, delimited by the presence of the gut, the two haemal arches noticeably stay separate and the haemal spine is absent. The next vertebrae or anterior caudal vertebrae belong to the tail; their haemal arches are fused from the $11^{\text {th }}$ vertebra and prolonged by a haemal spine. This latter spine is at its maximum length at V11 and decreases in length posteriorly. The anterior surface of the haemal arch is characterized by the presence of wide trough-like cavity which becomes narrower posteriorly. No intraspecific variation was noticed in the shape of vertebrae.

The centrum is made of two half spheres joined by their curved sides (Amphicoelic vertebrae), withchordal cavities connected by a thin hole. A pair of anterior processes and a pair of posterior processes protrude from the dorsal aspects of each centrum. The anterior and posterior processes are close to each other and lie 1-2 $\mathrm{mm}$ from one another with an 
external ligament bounding them together. Neural spines and arches project from the dorsal aspect of each vertebral centrum.

The first 4 vertebral centra differ qualitatively from the remaining abdominal vertebrae. The adjacent centra are joined together through the dorsal anterior processes of one vertebra which overlap to the dorsal posterior processes of the preceding vertebra, e.g. the dorsal anterior processes of the centrum of the $2^{\text {nd }}$ vertebra overlap substantially with the proximal portion of the dorsal posterior processes of the first centrum near the base of the neural spine. This overlap of processes is present for the first four vertebrae. In addition, these four vertebrae have parapophysis dorsally located relative to the parapophysis found on the abdominal rib-bearing vertebrae and located at the base of the neural spine. These ribs do not extend downwards to surround the viscera.
Vertebrae 5-10 have a typical abdominal vertebral morphology with well-developed anterior and posterior dorsal processes but gradually become less developed posteriorly to V10. In addition, the two portions of each centrum, dorsal and ventral, are connected to each other by bonetissue. In having both haemal arches and short ventrally located parapophyseal projections that articulate with ribs that extend ventrally around the viscera, vertebrae V5-V10are considered to have a transitional form. Finally, vertebrae 11-36 have a typical caudal vertebral morphology with reduced dorsal processes relative to the first 4 vertebrae, absence of ribs and parapophyseal articulations, and presence of haemal arches and spines. In the transitional and caudal regions, a prominent lateral ridge is clear along the midline of each centrum.

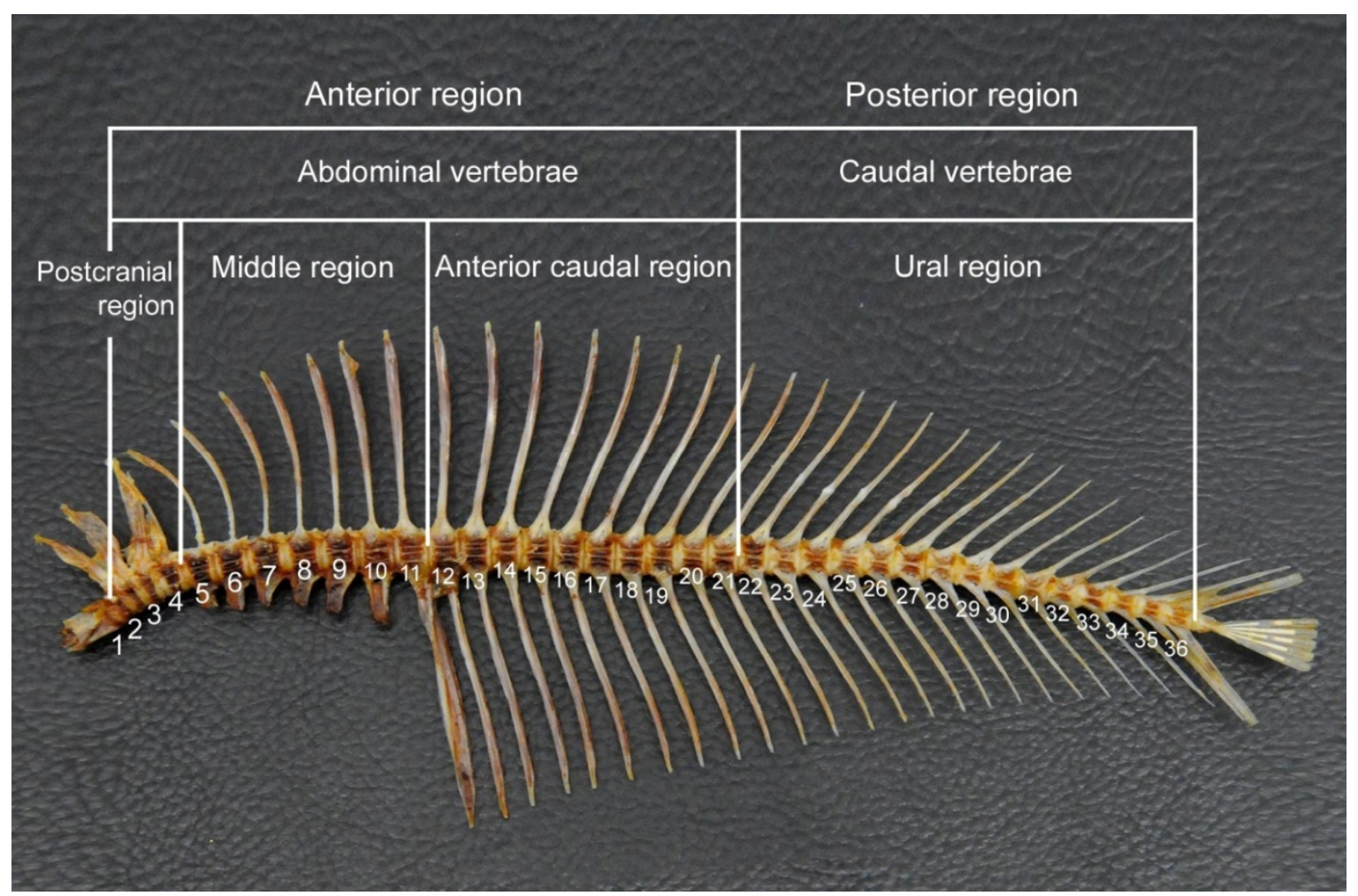

Fig. 1. Vertebral column of Pseudorhombus arsius showing regionalization

The vertebral column of Pseudorhombus arsius showed characteristic regionalization (fig.2, table 1). Firstly, the postcranial region, immediately at the back of the skull, ensures articulation with the latter and is composed of four vertebrae that present relatively important 
variations of their parameters. The first vertebra is a small vertebra with fine neural spine. There are no anterior zygapophyses in the first vertebra as this vertebra supports the skull; instead, it has two facets for the skull to rest on. In V2-V4, the anterior and the posterior zygapophyses are overlapped to greater degree. The development of the lateral parapophysis decreased posteriorly. Parapophyses of V1-V4 are moredorsally located relative to those of the abdominal vertebrae.

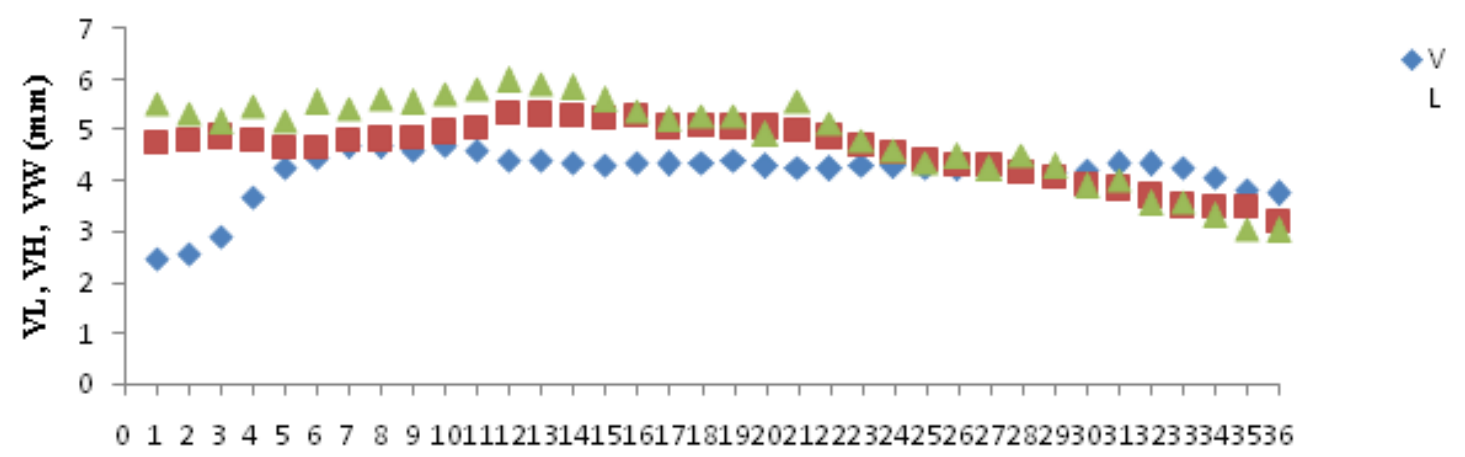

Ordinal number of vertebrae

Fig. 2. Relationship between vertebral length (VL), height (VH) and width (VW) and ordinal number of vertebrae of Pseudorhombus arsius

Secondly, the middle region appears to be made up of two morphological entities: the middle region (V5-V10) and the anterior caudal vertebrae (V11-V21). Here the length of the trunk vertebrae decreases progressively until it slightly increases around the $21^{\text {st }}$ vertebra. The width of the vertebrae exhibits a reverse trend and shows an increase until the $13^{\text {th }}$ vertebra, then a steady decrease until the $21^{\text {st }}$ vertebra. Vertebrae 5-10 can be considered as transitional form with both haemal arches and short ventrally located papapophyses that articulate with ribs that extend ventrally around the viscera. Middle region vertebrae have well developed anterior and posteriorzyg apophyses. In addition, these vertebrae have ribs that extend ventrally toward viscera. At V5, a lateral bony ridge separates the dorsal and ventral portions of each vertebra.

Thirdly, the ural region includes vertebrae V22-V36. It corresponds to the caudal peduncle and is characterized by a fall of the vertebral length and width. Vertebral length falls between V33-V36, while vertebral width falls between V26-V36.

The profiles corresponding to the three parameters measured on all the vertebrae were the same in all the specimens studied. The morphometric analysis shows that the vertebral axis of $P$. arsiusis complex with three main regions the first two of which are further divided into two sub-regions each, according to the changes of the parameters measured.

The vertebral profile given by the variation of the vertebral length along the axis shows three minima: one anterior at V5, one at the anterior caudal region at V17 and one posteriorly at V36. Between V4 and the next maximum vertebral length value at $\mathrm{V} 7$ the vertebral length increases steadily and then it remains steady until V10. After that, the length of the vertebrae decreases steadily until V29 after which there is only a slight decrease at V30-V32 and then there is a further, dramatic decrease down to minimum value at $\mathrm{V} 36$. 
Laith A. Jawad

Table 1. Average values (M) (mm) of length (LV), height (LH) and anterior width (LW) for the successive vertebrae if the vertebral column of Pseudorhombus arsius (SD = standard deviation)

\begin{tabular}{|c|c|c|c|c|c|c|}
\hline \multirow{2}{*}{ Ordinal number of vertebrae } & \multicolumn{2}{|c|}{ VL } & \multicolumn{2}{|c|}{ VH } & \multicolumn{2}{|c|}{ VW } \\
\hline & $M$ & SD & $M$ & SD & $M$ & SD \\
\hline 1 & 2.46 & 0.736 & 4.73 & 0.51 & 5.53 & 0.51 \\
\hline 2 & 2.57 & 0.50 & 4.80 & 0.43 & 5.34 & 0.43 \\
\hline 3 & 2.91 & 0.63 & 4.86 & 0.54 & 5.15 & 0.53 \\
\hline 4 & 3.68 & 0.57 & 4.79 & 0.62 & 5.48 & 0.61 \\
\hline 5 & 4.27 & 0.75 & 4.65 & 0.52 & 5.17 & 0.52 \\
\hline 6 & 4.45 & 0.93 & 4.67 & 0.50 & 5.55 & 0.51 \\
\hline 7 & 4.68 & 1.02 & 4.79 & 0.56 & 5.42 & 0.54 \\
\hline 8 & 4.66 & 1.04 & 4.81 & 0.59 & 5.6 & 0.57 \\
\hline 9 & 4.61 & 0.98 & 4.85 & 0.64 & 5.55 & 0.65 \\
\hline 10 & 4.69 & 1.04 & 4.96 & 0.59 & 5.72 & 0.57 \\
\hline 11 & 4.58 & 0.57 & 5.04 & 0.58 & 5.8 & 0.56 \\
\hline 12 & 4.41 & 0.51 & 5.31 & 0.60 & 5.98 & 0.61 \\
\hline 13 & 4.41 & 0.50 & 5.30 & 0.59 & 5.91 & 0.57 \\
\hline 14 & 4.37 & 0.49 & 5.26 & 0.59 & 5.84 & 0.58 \\
\hline 15 & 4.31 & 0.50 & 5.22 & 0.60 & 5.59 & 0.61 \\
\hline 16 & 4.35 & 0.41 & 5.26 & 0.67 & 5.37 & 0.66 \\
\hline 17 & 4.33 & 0.42 & 5.06 & 0.67 & 5.21 & 0.65 \\
\hline 18 & 4.34 & 0.41 & 5.09 & 0.58 & 5.26 & 0.58 \\
\hline 19 & 4.39 & 0.49 & 5.06 & 0.64 & 5.28 & 0.63 \\
\hline 20 & 4.29 & 0.44 & 5.05 & 0.59 & 4.91 & 0.58 \\
\hline 21 & 4.27 & 0.46 & 4.98 & 0.68 & 5.56 & 0.67 \\
\hline 22 & 4.23 & 0.46 & 4.87 & 0.71 & 5.12 & 0.71 \\
\hline 23 & 4.31 & 0.47 & 4.71 & 0.76 & 4.8 & 0.74 \\
\hline 24 & 4.28 & 0.51 & 4.54 & 0.53 & 4.61 & 0.52 \\
\hline 25 & 4.26 & 0.57 & 4.42 & 0.56 & 4.36 & 0.55 \\
\hline 26 & 4.24 & 0.59 & 4.29 & 0.57 & 4.48 & 0.56 \\
\hline 27 & 4.23 & 0.55 & 4.32 & 0.4 & 4.24 & 0.48 \\
\hline 28 & 4.21 & 0.44 & 4.18 & 0.62 & 4.51 & 0.62 \\
\hline 29 & 4.17 & 0.64 & 4.05 & 0.62 & 4.28 & 0.62 \\
\hline 30 & 4.22 & 0.62 & 3.93 & 0.64 & 3.89 & 0.63 \\
\hline 31 & 4.33 & 0.64 & 3.84 & 0.61 & 4.03 & 0.62 \\
\hline 32 & 4.33 & 0.68 & 3.70 & 0.69 & 3.56 & 0.67 \\
\hline 33 & 4.25 & 0.71 & 3.51 & 0.67 & 3.57 & 0.66 \\
\hline 34 & 4.08 & 0.79 & 3.48 & 0.60 & 3.31 & 0.61 \\
\hline 35 & 3.82 & 0.73 & 3.48 & 0.72 & 3.05 & 0.71 \\
\hline 36 & 3.75 & 0.66 & 3.18 & 0.68 & 3.02 & 0.70 \\
\hline
\end{tabular}

The vertebral height along the axis shows three minima: in the middle region at V5, in the anterior caudal region at V17 and in the ural region at V36. The maximum value is reached at V12 after which it fluctuates until V17 where the vertebral height starts to decrease steadily until V36 where it reaches its minimum value.

There are three minima for the vertebral width: at V3, V20 and V36. A sharp decrease occurs between V1 and V3. The fluctuation of the vertebral width between V4 and V28 may be divided into three sectors. The first sector, V4-V12, shows clear but variable fluctuation of the vertebral width. The second, V13-V21 and third sectors, V22-V28, differ from each other because of the increase in vertebral column width at V21. The fluctuation of vertebral width value in the first sector is steady while that of the second and third is more variable. This value drops dramatically at V30 and reached its minimum value at V36. 
The total number of vertebrae of $P$. arsius is 36 . There are 10 abdominal vertebrae and 26 caudal vertebrae. The vertebral aspect ratios for the abdominal and caudal regions are 0.71 and 0.94 respectively.

\section{DISCUSSION}

The vertebral column of Pseudorhombus arsius is a complex structure and it composed of four regions. This is evident through the biometric analysis of three vertebral dimensions, which suggests the division into the following four regions: 1) postcranial (anterior truncal); 2) middle; 3) anterior caudal; and 4) ural. The $2^{\text {nd }}$ and $3^{\text {rd }}$ regions are characterized by strong variations in vertebral parameters; in regions 1 and 3, these variations are more gradual and characterized by a decrease in the length, height and width of vertebrae (region 3 ).

The post-cranial region, immediately at the back of the head, insures the articulation with the skull. The first four vertebrae, V1-V4, form a morphological set with specific vertebral length and height. However these four vertebrae do not show completely different morphological characteristics compared with the other vertebrae (except for the first one). For $P$. arsius, the first vertebra plays as anterior ventral concavity which is articulated with the basioccipital. This first post-cranial vertebra is designed to articulate with the posterior region of the skull, forming with the next vertebra a link between the two main elements of the axial skeleton, which is a function that requires some morphological specificity [20]. The following six vertebrae, V5-V10, could be considered transition vertebrae because they show an increase in the vertebral biometric parameters [21].

The ural region starts with the $22^{\text {nd }}$ vertebra. It corresponds to the tail and is characterized by a decrease in the analyzed parameters.

As in other teleost fishes [20], the substitution of classical anatomical truncal and caudal region by more than two regions as in the case of the species under study, P. arsius, is probably linked to the mechanical constraints of swimming. Moreover, the antero-posterior variations of the three morphological parameters studied with the sudden variations in the poscranial and ural regions on the one hand, and the maximum in the middle regions on the other, favors this hypothesis [18]. The large tooth flounder has an anguilliform mode of swimming [3, 16, 25]. It swims on its side so that the undulation is vertical rather than horizontal. A very wide body span in flatfish is achieved both by a highly compressed body and elongated dorsal and anal fins [12]. The fact that the maximum values of the parameters occur around the $11^{\text {th }}-13^{\text {th }}$ vertebrae can be the structural response of these vertebrae to maximal mechanical constraints.

Regarding the third region, its specific parameter variation might express the major role performed by the caudal vertebrae in the motor process of swimming. The caudal skeleton responds to the alternate contraction of the intrinsic muscles on the dorsal and ventral sides of this region, thus torsion of the caudal peduncle is generated when they move suddenly from their hiding in the bottom of the sea [1].

The morphometric analysis of the vertebral column has revealed no significant difference between the variation of the vertebral length, height and width of each vertebra of $P$. arsius. Therefore, characterization of one vertebra along the vertebral column would be sufficient if it based only on one of these three parameters [4]. Furthermore, the morphology of the vertebrae of males and females are similar. This result supports that of 16 Kacemet al. (1998) on the morphology of the skeleton of Salmo salar. Similar results of regionalization of the vertebral column have been observed in fish species like Auzixthazard, where the vertebral column is divided into three morphologically distinct regions [8] and that of Lagocephalus sceleratus is deivided into five distinct regions [9].

The regionalization in the vertebral column of the species in question might develop through differences in the length of vertebrae, which in turn may be due to different 
mechanisms regulating vertebral growth in each region [5].

The similarity in the value of the aspect ratio between the abdominal and caudal regions, found in this study, may indicate that the changes in the vertebral length are closely linked between these two regions [24].

\section{CONCLUSION}

A morphometrical study of the length, height and width of the successive vertebrae constituting the vertebral axis of Pseudorhombus arsius permits a division of the vertebral column of this species into four morphologically distinct regions and profile of the vertebral column can be drawn accordingly. Differences in development in length of vertebrae in different regions might be behind this regionalization.

Acknowledgement: I would like to thank the Ministry of Fisheries Wealth, Marine Science and Fisheries Centre, the Ministry of Fisheries Wealth and the directorate of Agriculture and Fisheries Developmental Fund for giving me the opportunity to work on the fish samples from Sultanate of Oman and to provide for financial support.

\section{REFERENCES}

1. Bainbridge, R., 1958. Caudal fin and body movements in the propulsion of some fish. Journal of Experimental Biology 40, pp. 23-56.

2. Bemis, W. E. and Forey, P. L., 2001. Occipital structure and the posterior limits of the skull in actinopterygians. In: Ahlberg, P. (ed.). Major Events in Vertebrate Evolution. Taylor \& Francis, London. pp. 350-369.

3. Breder, C. M., 1926. The locomotion of fishes. Zoologica 4, pp. 159-256.

4. Desse J., Desse-Berset, N. and Rocheteau, M., 1989. Les profils rachidiens globaux. Reconstitution de la taille des poisons et appréciation du nombre minimal d'individus à partir des pièces rachidiennes. Review of Paléobiology 8, pp. 89-94.
5. Fjelldal, P. G., Nordgarden, U., Berg, A., Grotmol, S., Totland, G. K., Wargelius, A. and Hansen, T., 2005. Vertebrae of the trunk and tail display different growth rates in response to photoperiod in Atlantic salmon, Salmo salar L., post-smolts. Aquaculture 250, pp. 516-524.

6. Ford, E. 1937. Vertebral variation in teleostean fishes. Journal of Marine Biological Assciation of United Kigdom 22, pp. 1-60.

7. Grande, I. and Bemis, W. E., 1998. A comprehensive phylogenetic study of amiid fishes (Amiidae) based on comparative skeletal anatomy. An empirical search for interconnected patterns of natural history. Journal of Vertebrate Paleontology 18, pp. 1-690.

8. Jawad, L.A. and Al-Hassani, L., 2013. Some morphological studies on the vertebral column of the Silver-cheeked toadfish Lagocephalus sceleratus (Gmelin, 1789) (Family: Tetraodontidae) Collected from the Sea of Oman. Quaderni del Museo di Storia Naturale di Ferrara 1: 69-74

9. Jawad, L. A., Al-Hassani, L. and AlKharusi, L. H., 2013. On the morphology of the vertebral column of the frigate tuna, Auxisthazard (Lacepedea, 1800)(Family: Scombridae) collected from the Sea of Oman. Acta Musei Nationalis Pragae 69: 101-105.

10. Hoar, W. S. and Randall, D., 1978. Locomotion. In: Hoar W.S., Randall D.J. (eds.) Fish Physiology. Volume 7. Academic Press, New York.

11. Kacem, A., Meunier, F.J. and Bagliniere, J. L., 1998. A quantitative study of morphological changes in the skeleton of Salmo salar during its anadromous migration. Journal of Fish Biology 53, pp. 1,096-1,109.

12. Kubo, Y. and Asano, H., 1987. Growth type of vertebral centra and the hard tissue observed by microradiography of the rainbow trout. Nippon Suisan Gakkaishi 53, pp. 1,367-1,372. 
13. Kubo, Y. and Asano, H., 1990. Relative growth pattern and hard tissue of vertebral centra by microradiography of Bluefin tuna, bigeye tuna and skipjack. Nippon Suisan Gakkaishi 56, pp. 1,0211,027 .

14. Learm, J., 1976. The development, function and design of amphicoelous vertebrae in teleost fishes. Zoological Journal of the Linnaean Society 58, pp. 237-254.

15. LeDanois, Y., 1958. Systèmemusculaire. In: Grassé, P.P. (ed.), Traité de Zoologie, Vol. 13. Masson, Paris. pp. 783-817.

16. Lindsey, C. C., 1978. Form, function and locomotory habits in fish. In: Hoar W.S., Randall, D.J. (eds.). Fish Physiology. Academic Press, New York, pp. 1-100.

17. Ministry of Agriculture and Fisheries Wealth, 2011. Landing statistics for the year 201-2011. Department of Fisheries Statistics, Ministry of Agriculture and Fisheries Wealth, Muscat, Oman.

18. Pietsch, T. W., 1978. Evolutionary relationships of the sea moths (Teleostei: Pegassidae) with a classification of gasterosteiformes families. Copeiapp. 517529.

19. Ramzu, M., 1994 . Etude de la regionalization de lacolonnevertebrale en function des modes de nagechezlesteleosteens, Morphologie, histolohieetcroissance. These de doctorat, University of Paris-7, Fasc. 1(texte):
145 pp.; fasc. 2 (illustrations), 158 figs, $121 \mathrm{pp}$.

20. Ramzu, M., Meunier, F. J. and Schovaert, D., 1992. Morphological and histological characteristics of thevertebral axis zonation in the trout (Salmo trutta L.) (Teleostei, Salmonidae): possible functional implications. Oceanis, 18, pp. 85-91.

21. Ramzu, M. and Meunier, F. J., 1999. Descripteursmorphologique de la zonation de la colonne vertébrale chez la truite areen-ciel Oncorhynchus mykiss (Walbaum, 1792) (Teleostei, Salmonidae). Annales de Science Naturale 3, pp. 87-97.

22. Videler, J. J., 1993. Fish Swimming. Chapman \& Hall, London.

23. Vronskii, A. A. and Nikolaitchouk, L. A., 1989. Morphologie Fonctionnelle de la Musculature Locomotrice du Corps des Poissons. La Pensée Scientifique, Kiev.

24. Ward, A. B. and Brainerd, E. L., 2007. Evolution of axial patterning in elongate fishes. Biological Journal of the Linnaean Society 90, pp. 97-116.

25. Webb, P. W., 1978. Hydrodynamique et énergétique de la propulsion des poisons. Bulletin de L'Office des recherches sur les pêcheries du Canada.

26. Weihs, D., 1989. Design features and mechanics of axial locomotion in fish. American Zoologist 24, pp. 107-120. 